\title{
Two ENU-Induced Alleles of Atp2b2 Cause Deafness in Mice
}

\author{
Marina R. Carpinelli ${ }^{1,2,4,5^{*}}$, Michael G. Manning ${ }^{1,2}$, Benjamin T. Kile ${ }^{4,5}$, A. Burt Rachel ${ }^{1,4}$
}

1 Murdoch Childrens Research Institute, Royal Children's Hospital, Parkville, Victoria, Australia, 2 The HEARing Cooperative Research Centre, University of Melbourne, Melbourne, Victoria, Australia, 3 Department of Genetics, University of Melbourne, Melbourne, Victoria, Australia, 4 Walter and Eliza Hall Institute of Medical Research, Parkville, Victoria, Australia, 5 Department of Medical Biology, University of Melbourne, Melbourne, Victoria, Australia

\begin{abstract}
Over 120 loci are known to cause inherited hearing loss in humans. The deafness gene has been identified for only half of these loci. With the aim of identifying some of the remaining deafness genes, we performed an ethylnitrosourea mutagenesis screen for deaf mice. We isolated two mutants with semi-dominant hearing loss, Deaf11 and Deaf13. Both contained causative mutations in Atp2b2, which encodes the plasma membrane calcium ATPase 2. The Atp2b2 Deaf11 mutation leads to a p. I1023S substitution in the tenth transmembrane domain. The Atp2b2 $2^{\text {Deaf13 }}$ mutation leads to a $p$. R561S substitution in the catalytic core. Mice homozygous for these mutations display profound hearing loss. Heterozygotes display mild to moderate, progressive hearing loss.
\end{abstract}

Citation: Carpinelli MR, Manning MG, Kile BT, Rachel AB (2013) Two ENU-Induced Alleles of Atp2b2 Cause Deafness in Mice. PLoS ONE 8(6): e67479. doi:10.1371/journal.pone.0067479

Editor: Harold A. Burgess, National Institutes of Health / NICHD, United States of America

Received January 31, 2013; Accepted May 14, 2013; Published June 24, 2013

Copyright: $\odot 2013$ Carpinelli et al. This is an open-access article distributed under the terms of the Creative Commons Attribution License, which permits unrestricted use, distribution, and reproduction in any medium, provided the original author and source are credited.

Funding: The authors acknowledge the financial support of the HEARing CRC (www.hearingcrc.org), established and supported under the Australian Government's Cooperative Research Centres Program; the Victorian State Government's Operational Infrastructure Support Program; the Australian Government's NHMRC IRIISS (www.nhmrc.gov.au); a National Collaborative Research Infrastructure Strategy grant to the Australian Phenomics Network (www.australianphenomics.org.au); and the Garnet Passe and Rodney Williams Memorial Foundation (www.gprwmf.org.au, fellowship to MRC). The funders had no role in study design, data collection and analysis, decision to publish, or preparation of the manuscript.

Competing interests: The authors have declared that no competing interests exist.

*E-mail: marina.carpinelli@mcri.edu.au

\section{Introduction}

Inherited hearing loss affects 1 in 500 children [1]. Over 120 loci have been linked to non-syndromic hearing loss in humans but only 57 genes have been identified (http:// hereditaryhearingloss.org) [2], leaving many patients without a genetic diagnosis. Development of new genetic tests for hearing loss would provide families with information such as likelihood of progression, suitability for cochlear implant, carrier status of other children and likelihood of having another child with hearing loss.

After travelling through the outer and middle ear, sound reaches the cochlea, which is divided into three fluid-filled compartments [3]. The scala vestibuli and scala tympani contain perilymph and the scala media contains endolymph [3]. Endolymph contains a high concentration of potassium ions and also contains calcium ions [3]. Hair cells project actin-filled stereocilia from the organ of Corti into the endolymph [3]. Sound waves bend the stereocilia, stretching the tip links between them and pulling open a mechanoelectrical transduction (MET) channel [3]. This allows potassium and calcium ions from the endolymph to enter the hair cell, causing the hair cell to signal to synapsing neurons of the auditory nerve [3].

We performed a mouse mutagenesis screen to isolate dominant mutations causing hearing loss. In this paper we describe the characterization of two mutants with semidominant hearing loss. The deafness mutations in these mice lie in Atp2b2, which encodes the plasma membrane calcium ATPase 2 (PMCA2). This pump is expressed in cochlear hair cells [4] and exports calcium into the endolymph (reviewed in 5). Ten previously published Atp $2 b 2$ mutant mice display hearing loss, vestibular problems and ataxia (table 1) [6-14]. Our new alleles of Atp2b2 identify two amino acids that are functionally important in PMCA2.

\section{Materials and Methods}

\section{Mice}

All mice were bred and maintained at the Walter and Eliza Hall Institute of Medical Research (WEHI). Animals were group-housed in individually ventilated micro-isolator cages (Airlaw, Smithfield, NSW, Australia) enriched with a plastic house/toy and sunflower seeds on a 12-hour light/dark cycle. Animals were fed standard Barastoc mouse chow (Ridley 
Table 1. Published mouse Atp2b2 alleles.

\begin{tabular}{llllll}
\hline Allele & Derivation & Mutation & Inheritance & Effect & Ref \\
\hline$d f w$ & spontaneous & point & recessive & G283S & {$[6]$} \\
$d f w$-2J & spontaneous & deletion & semidominant & Null allele & {$[6]$} \\
$d f w$-3J & spontaneous & deletion & semidominant & Null allele & {$[7]$} \\
Elfin & ENU & point & semidominant & I655N & {$[8]$} \\
jog & spontaneous & insertion & recessive & $\downarrow$ expression & {$[9]$} \\
M1Mae & spontaneous & point & semidominant & T692K & {$[10]$} \\
Obv & ENU & point & semidominant & S877F & {$[11]$} \\
tm1Ges & gene targeting & insertion & semidominant & Null allele & {$[12]$} \\
Tmy & ENU & point & semidominant & E629K & {$[13]$} \\
wri & spontaneous & point & semidominant & E412K & {$[14]$} \\
\hline Ref reference. & & & &
\end{tabular}

Table 2. Primers used for mutation identification.

\begin{tabular}{ll}
\hline Primer & Sequence \\
\hline MC47 & GACCCGCAGATAGTGATCGT \\
MC48 & TTCCCTGGTATGGGCAGTAG \\
MC99 & CCTCGGGGTCAAAATGATAA \\
MC100 & GTGATGCAGACACCCACAAC \\
\hline
\end{tabular}

AgriProducts, Melbourne, VIC, Australia) and water ad libitum. The WEHI animal ethics committee approved this work in project numbers 2008.023 and 2011.016.

\section{Mutagenesis Screen}

Male BALB/c mice were intraperitoneally injected with 85 $\mathrm{mg} / \mathrm{kg}$ ethylnitrosourea (ENU) (Sigma-Aldrich, Castle Hill, NSW, Australia) weekly for 3 weeks as described [15]. Treated animals were rested for 12 weeks before mating with untreated BALB/c females to produce first generation $\left(G_{1}\right)$ progeny. These mice were acoustic startle response (ASR)-tested at 8 weeks of age. Animals with maximum startle amplitude below 200 arbitrary units were test-mated to determine heritability of the phenotype. Mutant strains were backcrossed for 10 generations in order to breed out irrelevant ENU-induced mutations.

\section{Acoustic Startle Response}

ASR was measured using an SR-LAB system (San Diego Instruments, San Diego, CA, USA). Testing was conducted in the light phase of the light cycle and the testing environment was illuminated. Each mouse was restrained in a perspex chamber and acclimatized to background white noise of $70 \mathrm{~dB}$ SPL for $1 \mathrm{~min}$. Trials were presented in pseudorandom order and separated by intervals of 3-8 sec. Mice underwent 6 background noise trials and 6 each of 85, 90, 95, 100 and 115 $\mathrm{dB}$ SPL $40 \mathrm{msec}$ white noise pulse trials. After deleting the largest and smallest values, the average startle amplitude for each stimulus was calculated and plotted against sound intensity using Prism v 6.0b software (GraphPad Software Inc, La Jolla, CA, USA).

\section{Auditory Brainstem Response}

Mice were anaesthetized by intraperitoneal injection of 100 $\mathrm{mg} / \mathrm{kg}$ ketamine and $20 \mathrm{mg} / \mathrm{kg}$ xylazine and their eyes were moistened with lacrilube. Body temperature was maintained with a $37^{\circ} \mathrm{C}$ heat pad inside a custom-made faraday chamber. The faraday chamber was placed inside a sound attenuation cabinet, the Habitest isolation cubicle model H10-24A (Coulbourn Instruments, Whitehall, PA, USA). A free-field magnetic speaker (model FF1, Tucker Davis Technologies, Alachua, Florida, USA) was placed $10 \mathrm{~cm}$ from the left pinna and computer-generated clicks (100 $\mu \mathrm{sec}$ duration, with a spectrum of $0-50 \mathrm{kHz}$ ) and pure tone stimuli of $4,8,16$ and 32 $\mathrm{kHz}$ were presented with maximum intensities of $100 \mathrm{~dB}$ SPL. Auditory brainstem responses (ABRs) were recorded differentially using subdermal needle electrodes (S06666-0, Rochester Electro-Medical, Inc., Lutz, FL, USA). These were positioned at the vertex of the skull (+ve) and on the left cheek (-ve) with a ground on the hind left leg. ABRs were averaged over 512 repetitions of the stimulus. ABR traces were analyzed to determine ABR threshold using BioSig software (Tucker Davis Technologies). The threshold was defined as the lowest intensity stimulus that reproducibly elicited an ABR.

\section{Mutation Identification}

Exome sequencing of two +/Deaf11 and two +/Deaf13 mice was performed at the Australian Genome Research Facility (AGRF) using the 100803_MM9_exome_rebal_2_EZ_HX1 exome capture array (Roche Nimblegen, Madison, WI, USA), TruSeq Sample Preparation Kit (Illumina, San Diego, CA, USA) and HiSeq2000 Sequencing System (Illumina). Sequence analysis was performed by the Bioinformatics Unit of the Australian Phenomics Facility (APF) using a custom workflow to align the sequence reads to the reference genome (C57BL/6 $\mathrm{NCBI} \mathrm{m} 37$ ), filter the raw single nucleotide variant (SNV) calls and generate a list of candidate SNVs as described [16]. Deepsequencing datasets were deposited into the National Center for Biotechnology Information (NCBI) Sequence Read Archive (http://www.ncbi.nlm.nih.gov/sra) with the run accession numbers SRR822874, SRR822875, SRR822876 and SRR822877.

Atp2b2 SNVs were amplified using primers MC47 and MC48 (table 2) in Deaf11 mice and primers MC99 and MC100 in Deaf13 mice. $25 \mu \mathrm{l}$ PCR reactions contained $2 \mu$ genomic DNA, 1xPCR buffer (Life Technologies, Mulgrave, VIC, Australia), $500 \mathrm{nM}$ each primer, $200 \mathrm{nM}$ dNTPs, $1.5 \mathrm{mM} \mathrm{MgCl}_{2}$ and $0.625 \cup$ Taq DNA polymerase (Life Technologies). Reactions were incubated at $94^{\circ} \mathrm{C}$ for 3 min then for 30 cycles of $94^{\circ} \mathrm{C}$ for $45 \mathrm{sec}, 55^{\circ} \mathrm{C}$ for $30 \mathrm{sec}$ and $72^{\circ} \mathrm{C}$ for $90 \mathrm{sec}$, with a final extension at $72^{\circ} \mathrm{C}$ for $10 \mathrm{~min}$. PCR products were visualized by agarose gel electrophoresis.

Unincorporated nucleotides and primers were removed with Exo-SAP-IT exonuclease (Affymetrix, Santa Clara, CA, USA) according to the manufacturer's instructions. $10 \mu \mathrm{l}$ sequencing reactions containing $3 \mu \mathrm{l} \mathrm{PCR}$ product, $160 \mathrm{nM}$ primer, $2 \mu \mathrm{l}$ BigDye terminator $v 3.1$ (Life Technologies) and $1 \mu \mathrm{l} 5 \mathrm{x}$ buffer (Life Technologies) were incubated at $96^{\circ} \mathrm{C}$ for $2 \mathrm{~min}$, followed by 25 cycles of $96^{\circ} \mathrm{C}$ for $10 \mathrm{sec}, 50^{\circ} \mathrm{C}$ for $5 \mathrm{sec}$ and $60^{\circ} \mathrm{C}$ for 4 $\min$. Sequencing products were precipitated by addition of $75 \mu \mathrm{l}$ 
$200 \mathrm{nM} \mathrm{\textrm {MSO } _ { 4 }}$ in $70 \%$ ethanol. After $15 \mathrm{~min}$ incubation samples were centrifuged at $15,800 \mathrm{~g}$ for $15 \mathrm{~min}$. Pellets were washed with $70 \%$ ethanol, dried at $37^{\circ} \mathrm{C}$ and submitted to the AGRF for capillary separation. Sequencing electropherograms were aligned using Seqman v 10.1 software (DNASTAR, Madison, WI, USA). The NCBI protein database (http:// www.ncbi.nlm.nih.gov/protein/) entry Q9R0K7.2 was used to assign domains to the PMCA2 amino acid sequence.

\section{Linkage Mapping}

An Atp2b2 Deaf11/Deaf11 mouse was crossed to a C57BL/6 mouse to generate $N_{1}$ offspring. $N_{1}$ mice were intercrossed to produce $87 \mathrm{~N}_{1} \mathrm{~F}_{1}$ offspring, which were ABR-tested at 8 weeks of age. Genomic DNA was extracted from liver as described [17] and genotyped for single nucleotide polymorphisms (SNPs) on chromosome 6 using the Amplifluor SNPs HT genotyping system FAM-JOE (Merck Millipore, Kilsyth, VIC, Australia) and primers listed in Table S1. DNA was vacuumdried onto a 384 well plate. $5 \mu \mathrm{l}$ PCR reactions containing 0.15 $\mu \mathrm{M}$ each forward primer, $2.25 \mu \mathrm{M}$ reverse primer, $0.2 \mathrm{mM}$ each dNTP (Merck Millipore), 1xFAM (Merck Millipore), 1xJOE (Merck Millipore), 1xS+ mix (Merck Millipore) and $0.05 \mu \mathrm{l}$ titanium Taq DNA polymerase (Clontech Laboratories, Mountain View, CA, USA) were added to the plate using an epMotion 5070 robot (Eppendorf, South Pacific, North Ryde, NSW, Australia). PCR reactions were incubated at $94^{\circ} \mathrm{C}$ for 5 min, followed by 20 cycles of $94^{\circ} \mathrm{C}$ for $10 \mathrm{sec}, 55^{\circ} \mathrm{C}$ for $5 \mathrm{sec}$, $72^{\circ} \mathrm{C}$ for $10 \mathrm{sec}$, followed by 22 cycles of $94^{\circ} \mathrm{C}$ for $10 \mathrm{sec}, 55^{\circ} \mathrm{C}$ for $20 \mathrm{sec}, 72^{\circ} \mathrm{C}$ for $40 \mathrm{sec}$, followed by a final extension at $72^{\circ} \mathrm{C}$ for $3 \mathrm{~min}$. Fluorescence was measured with an infinite M200PRO plate reader (Tecan, Männedorf, Switzerland) using Magellan $\vee 7.1$ software (Tecan). FAM was excited at $490 \mathrm{~nm}$ and emission measured at $530 \mathrm{~nm}$. JOE was excited at $520 \mathrm{~nm}$ and emission measured at $560 \mathrm{~nm}$. Results were visualized and genotypes assigned using assayauditorEP.xls (Merck Millipore) and excel $v$ 12.2.0 software (Microsoft, Redmond, WA, USA).

\section{Histology}

All mice used for histology had previously been ABR-tested at 4 and 8 weeks of age. Mice were euthanized by intraperitoneal injection of $400 \mathrm{mg} / \mathrm{kg}$ ketamine and $80 \mathrm{mg} / \mathrm{kg}$ xylazine. After cessation of breathing, PBS was perfused through each animal via a cannula inserted into the left ventricle for $5 \mathrm{~min}$, followed by $10 \%$ neutral buffered formalin for $5 \mathrm{~min}$. Cochleae were dissected from the temporal bones and post-fixed for $1 \mathrm{hr}$ at room temperature. Cochleae were washed in tris-buffered saline and decalcified in 10\% EDTA for 5 days at $4{ }^{\circ} \mathrm{C}$ with gentle rolling. Cochleae were oriented in $1 \%$ agarose in PBS in $10 \mathrm{~mm} \times 10 \mathrm{~mm} \times 5 \mathrm{~mm}$ cryomolds (Sakura Finetek, Torrance, CA, USA) and paraffin-embedded. $2 \mu \mathrm{m}$ sections were cut parallel to the modiolus using a microtome and stained with hematoxylin and eosin (H\&E). Sections were imaged with a DM1000 compound microscope (Leica Microsystems, North Ryde, Australia) and DFC450 C camera (Leica Microsystems).

\section{Statistical Analysis}

One-way ANOVA and Dunnett's multiple comparison test were performed using Prism 6 software (GraphPad Software Inc.).

\section{Results}

We undertook an ENU mutagenesis screen for hearing loss in which we screened $1,462 \mathrm{G}_{1}$ mice for low ASR. Control $\mathrm{BALB} / \mathrm{c}$ mice consistently displayed maximum startle amplitude above 200 arbitrary units at $115 \mathrm{~dB}$ SPL (data not shown). Therefore, the criterion used to identify $G_{1}$ mice for re-testing was maximum startle amplitude below 200 arbitrary units. $G_{1}$ mice displaying a consistent low ASR were progeny-tested. This led to the isolation of 14 mutant lines with dominant, low ASR. Many of these will be described in future publications. In this paper we describe two of these mutant lines, Deaf11 and Deaf13.

Genomic DNA from two +/Deaf11 and two +/Deaf13 mice was exome-enriched and massively parallel sequenced. Eighty-nine percent of the consensus coding sequence (CCDS) exome was sequenced at least 4-fold (Table S2). The average depth of sequencing was between 37 and 69-fold. Between 25 and 1459 SNVs were identified in each sample. Visual comparison revealed that all samples contained a SNV in Atp2b2. These SNVs were confirmed by Sanger DNA sequencing. In Deaf11 mice a c.3068T>G mutation in exon 17 encodes a p. I1023S substitution in the tenth transmembrane domain of PMCA2 (Figure 1A-B). In Deaf13 mice a c.1681C>A mutation in exon 9 encodes a p. R561S substitution in the catalytic core of the PMCA2 pump (Figure 1C-D) [18]. Amino acid alignments indicate that R561 is conserved through evolution while 11023 is conserved or substituted with the similar amino acid, leucine (Figure 1E-F). This indicates that these amino acids are functionally important in PMCA2. As these SNVs are not present in the WEHI BALB/c mouse strain (data not shown), they are likely to be ENU-induced mutations.

Deaf11 and Deaf13 mice displayed normal body weight at 8 weeks of age (data not shown). We performed ABR tests to determine whether the low ASR was caused by hearing loss. ABR thresholds at 4, 8, 16 and $32 \mathrm{kHz}$ and for broad frequency click stimuli were determined at 4 and 8 weeks of age in

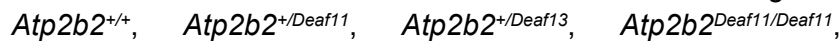

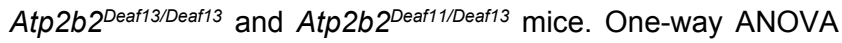
showed a statistically significant difference between mean thresholds at all frequencies tested (Table S3). Dunnett's test was then used to compare mean thresholds to those of Atp $2 b 2^{+/+}$mice, with a multiplicity-adjusted $p$-value of less than 0.01 taken as statistically significant. Atp2b2 Deaf1/Deaf11 and Atp2b2 $2^{\text {Deaf13/Deaf13 }}$ mice had profound hearing loss by 4 weeks of age. At this age, Atp $2 b 2^{+/ D e a f 13}$ mice had high frequency hearing loss (Figure 2A). By 8 weeks of age, Atp $2 b 2^{+/ \text {Deaf11 }}$ and Atp $2 b 2^{+/}$ Deaf13 mice displayed hearing loss at middle and high frequencies. The profound hearing loss observed in Atp2b2 $2^{\text {Deaf11/Deaf11 }}$ and Atp2b2 $2^{\text {Deaf13/Deaf13 }}$ mice also occurred in Atp2b2 $2^{\text {Deaf1/Deaf13 }}$ mice (Figure 2B). The lack of complementation between Deaf11 and Deaf13 indicated that 


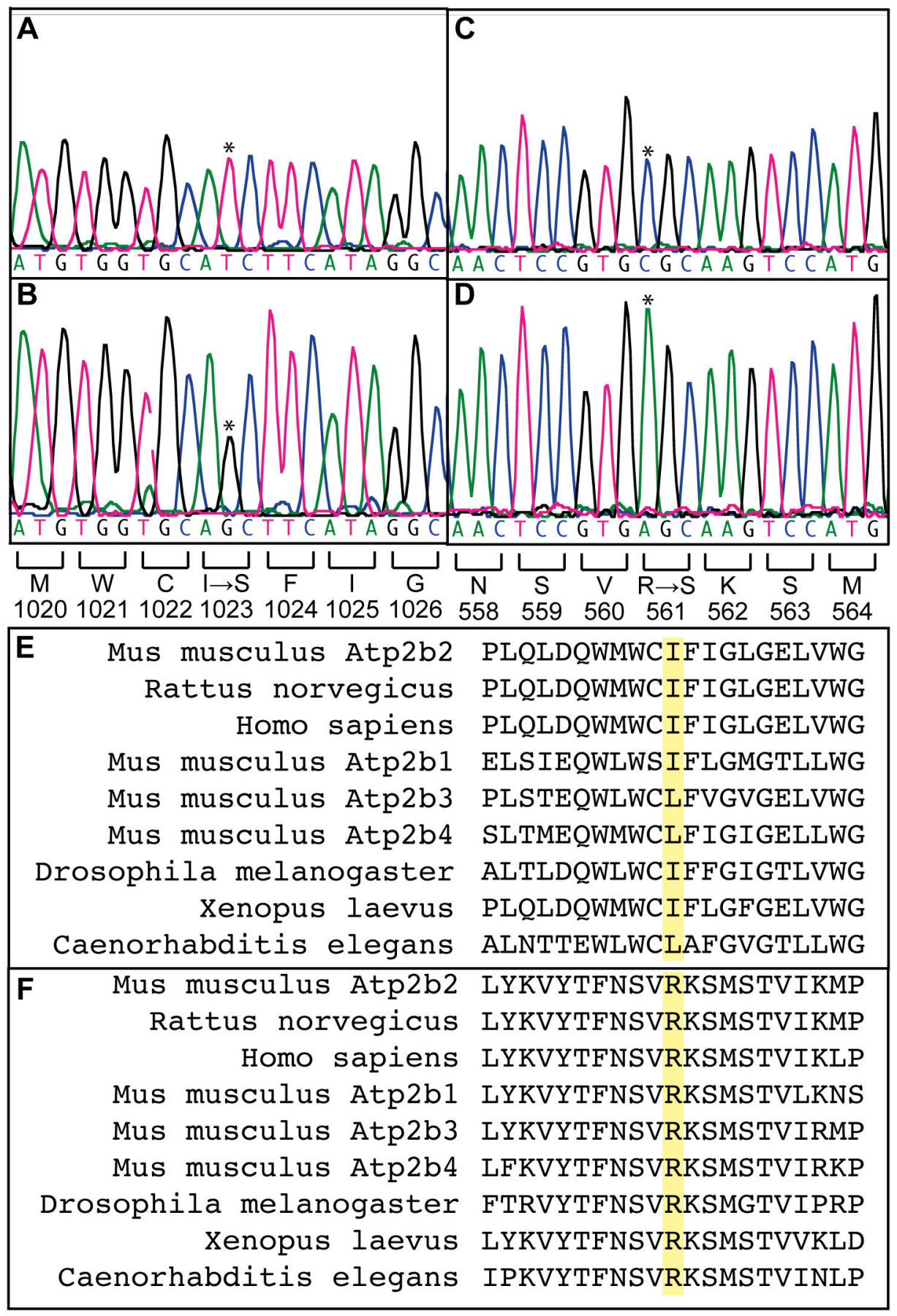

Figure 1. Deaf11 and Deaf13 mice harbor point mutations in Atp2b2. DNA sequence electropherograms of exon 17 in A) $+/+$ and B) Deaf11/Deaf11 mice. Results are representative of four +/+, 14 +/Deaf11 and 10 Deaf11/Deaf11 mice. DNA sequence electropherograms of exon 9 in C) +/+ and D) Deaf13/Deaf13 mice. Results are representative of two +/+, four +/Deaf13 and four Deaf13/Deaf13 mice. Mutation sites are marked by asterisks. Predicted effect on amino acid sequence is shown below. E) Amino acid sequence alignments for regions surrounding predicted Deaf11 and F) Deaf 13 amino acid substitutions (yellow). Alignments were performed with Clustal Omega (http://www.ebi.ac.uk/Tools/msa/clustalo/) using protein sequences Q9R0K7.2, P11506.2, Q01814.2, NP_080758.1, NP_796210.2, AAI09173.1,NP_001033803.3, NP_001087020.1 and CAA09303.1.

doi: 10.1371/journal.pone.0067479.g001 

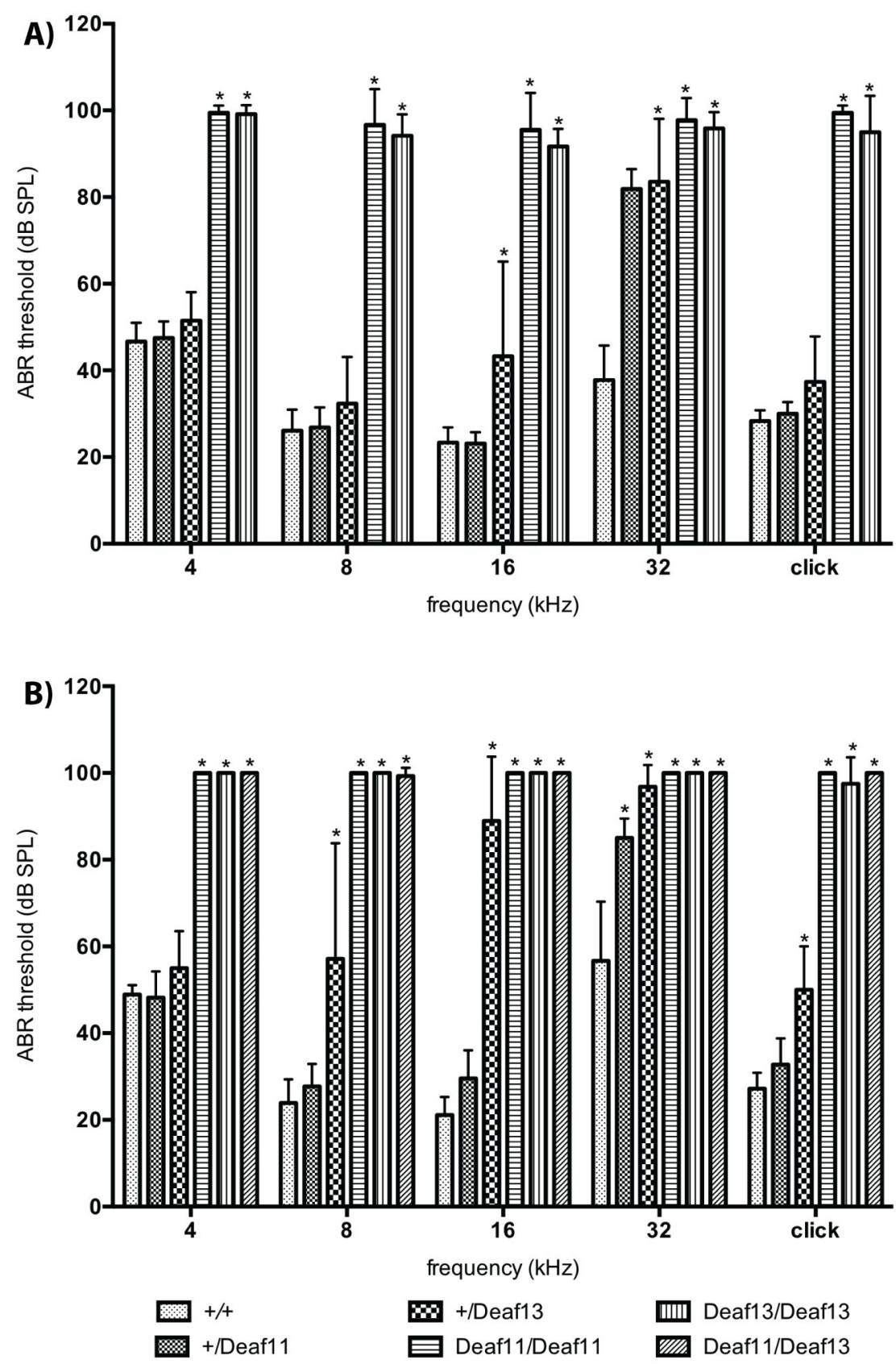

Figure 2. Deaf11 and Deaf13 mice display hearing loss. Mean ABR thresholds at A) 4 and B) 8 weeks of age; $A t p 2 b 2^{+/+} \mathrm{n}=3$

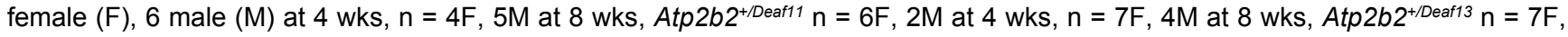

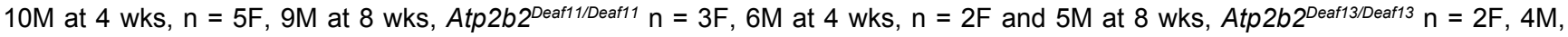
Atp2b2 ${ }^{\text {Deaf11/Deaf13 }} \mathrm{n}=4 \mathrm{~F}, 3 \mathrm{M} ;{ }^{*} \mathrm{p}<0.01$ versus Atp2b2 ${ }^{+/+}$; Error bars show standard deviation.

doi: 10.1371/journal.pone.0067479.g002

the causative mutations were allelic. Gender had no statistically significant effect on ABR thresholds.

These Atp2b2 mutations may have been causative of hearing loss or irrelevant. As each $\mathrm{G}_{1}$ mouse harbors about 43 penetrant ENU-induced mutations [19], or one every $63 \mathrm{Mb}$, irrelevant mutations are unlikely to be genetically linked to hearing loss. We performed meiotic mapping in order to determine whether the Atp2b2 $2^{\text {Deaf11 }}$ mutation was genetically linked to hearing loss (Figure 3). We crossed an Atp2b2 $2^{\text {Deaf11 }}$ Deaf11 BALB/c mouse to an Atp2b2 ${ }^{+/+}$C57BL/6 mouse. We chose this strain partly because $\mathrm{C} 57 \mathrm{BL} / 6$ mice have similar $\mathrm{ABR}$ thresholds to BALB/c mice [20]. Offspring were intercrossed to generate $87 \mathrm{~N}{ }_{1} F_{1}$ mice. These were ABR-tested and genotyped for SNPs between 109 and $130 \mathrm{Mb}$ on chromosome 


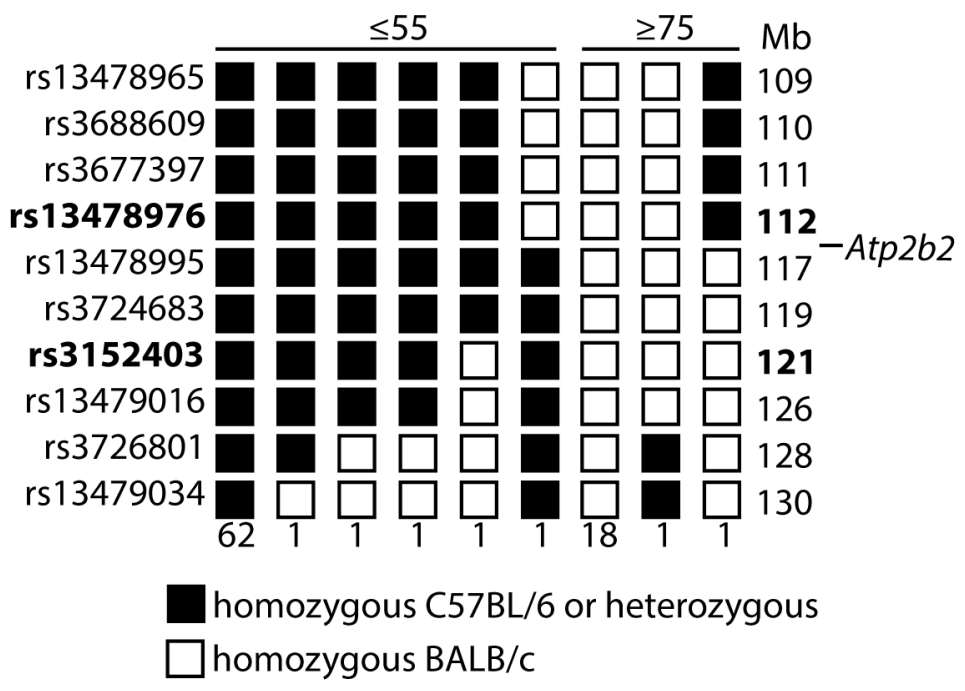

Figure 3. The Deaf11 mutation is linked to chromosome 6. A Deaf11/Deaf11 BALB/c mouse was crossed to a $+/+\mathrm{C} 57 \mathrm{BL} / 6$ mouse and the offspring intercrossed to generate $87 \mathrm{~N}_{1} \mathrm{~F}_{1}$ mice. Mice were divided into those with a click $A B R$ threshold $\leq 55 \mathrm{~dB}$ SPL on left $(+/+$ or $+/$ Deaf11) and those with a threshold $\geq 75 \mathrm{~dB}$ SPL on right (Deaf11/Deaf11). All mice were genotyped for SNPs on chromosome 6. SNP names and locations are listed on the left and right respectively (assembly GpCm38, database SNP, http:// www.ncbi.nlm.nih.gov/projects/SNP/). The numbers of mice displaying each haplotype are listed below. Informative recombinations indicate that the Deaf11 causative mutation lies between rs13478976 at $112 \mathrm{Mb}$ and rs3152403 at $121 \mathrm{Mb}$. Atp2b2 is located at 113 $\mathrm{Mb}$.

doi: 10.1371/journal.pone.0067479.g003

6. Informative recombinations allowed us to localise the Deaf11 mutation to between the SNPs rs13478976 at $112 \mathrm{Mb}$ and rs3152403 at $121 \mathrm{Mb}$. This region encompasses the Atp2b2 gene at $113 \mathrm{Mb}$, indicating that the Atp2b2 Deaf11 mutation is causative of the hearing loss in Deaf11 mice. As the Deaf11 and Deaf13 mutations are allelic, we can infer that the Atp2b2 $2^{\text {Deaf13 }}$ mutation is causative of hearing loss in Deaf13 mice.

PMCA2 is expressed in cochlear hair cells [4] and facilitates export of calcium into endolymph [5]. Although the primary role of PMCA2 is not in hair cell survival, hair cells could die as a secondary effect of insufficient PMCA2 activity. We examined this by collecting mid-modiolar cochlear sections from Atp $2 b 2^{+/+}$, Atp2b2 $2^{\text {Deaf11/Deaf11 }}$ and Atp2b2 Deaf13/Deaf13 mice at 8 weeks of age. As these mice were ABR-tested at 4 and 8 weeks of age, we cannot exclude the possibility that their cochlear hair cell survival was affected by this test. Three outer hair cells and one inner hair cell were apparent in the middle turn of Atp2b2 $2^{+/+}$cochlea. The Atp2b2 Deaf11/Deaf11 and Atp $2 b 2^{\text {Deaf13/Deaf13 }}$ hair cells had abnormal morphology indicative of degeneration (Figure 4). These results suggest that the loss of PMCA2 activity may lead to degeneration of hair cells in Atp2b2 $2^{\text {Deaf11/Deaf11 }}$ and Atp2b2 $2^{\text {Deaf13/Deaf13 }}$ mice.

\section{Discussion}

This study demonstrates that isoleucine 1023 and arginine 561 are functionally important in PMCA2. Isoleucine 1023 lies in the $10^{\text {th }}$ transmembrane domain. In Deaf11 mice this hydrophobic amino acid has been substituted with the polar amino acid serine. This may disrupt insertion of PMCA2 into the cell membrane. Arginine 561 lies in the catalytic core of the pump. In Deaf13 mice this basic amino acid has been replaced with the polar amino acid serine. This may disrupt the enzymatic activity of PMCA2. There are now eight published mouse mutants with amino acid substitutions disrupting PMCA2 activity (table 1). These will help to elucidate the molecular mechanism whereby PMCA2 exports calcium from the cell.

A number of observations suggest that the Deaf11 and Deaf13 alleles are hypomorphic. Atp2b2 Deaf1//Deaf11 and Atp2b2 $2^{\text {Deaf13/Deaf13 }}$ mice do not display ataxia or stunted growth, as observed in mice homozygous for the null allele [12]. Furthermore, Atp2b2 $2^{\text {Deaf11/+ }}$ and Atp2b2 $2^{\text {Deaf13/+ }}$ mice have milder hearing loss than mice heterozygous for the null allele [12]. The Deaf11 and Deaf13 mice may prove useful for those wishing to study milder forms of Atp2b2-induced hearing loss.

The mechanism whereby decreased PMCA2 activity causes hearing loss in Deaf11, Deaf13 and other Atp2b2 mutant mice is unknown. Atp2b2 dfw-2J/dw-2J mice display an abnormally low calcium concentration in endolymph [21]. This corresponds with low endocochlear potential, which would be expected to disrupt mechanoelectrical transduction [21]. Low calcium concentration in endolymph could also interfere with other calcium-dependent processes in hearing. For example, tip links are composed of the calcium-binding proteins cadherin 23 and protocadherin 15 [22] and break in the absence of calcium [23].

Middle turn cochlear hair cells in Atp2b2 Deaf1/Deaf11 and Atp2b2 $2^{\text {Deaf13/Deaf13 }}$ mice have abnormal morphology at 8 weeks of age. Cochlear hair cells degenerate in other Atp2b2 mutant 

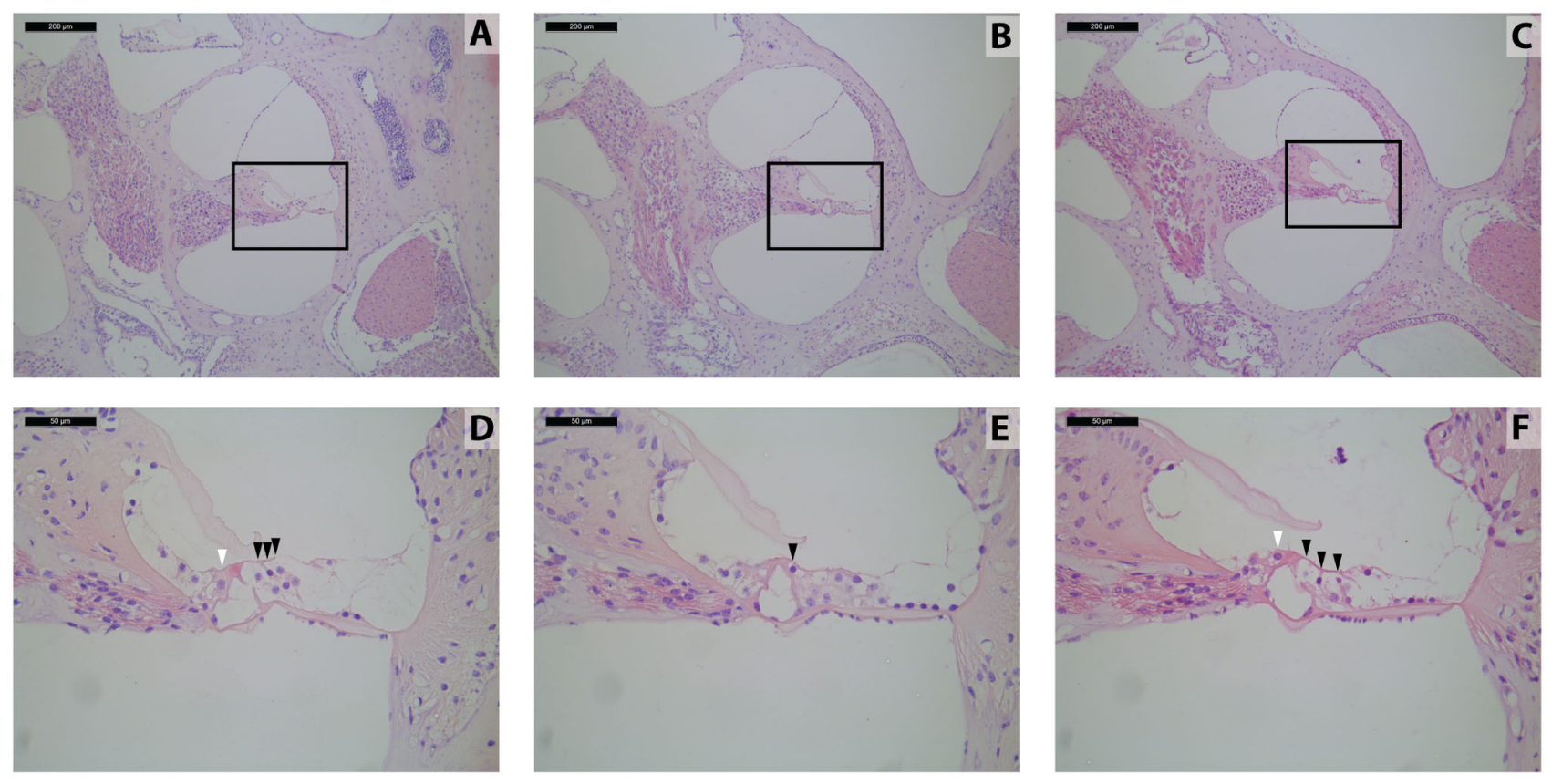

Figure 4. Deaf11 and Deaf13 cochlear hair cells are morphologically abnormal. Middle cochlear turn sections at 8 weeks of age; Upper panels 100x magnification, scale bar $200 \mu \mathrm{m}$; Lower panels $400 x$ magnification, scale bar $50 \mu \mathrm{m}$; A, D) Atp2b2 $2^{++}$B, E)

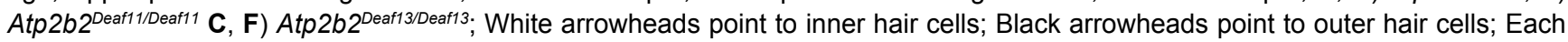
section is representative of 4 cochleae.

doi: 10.1371/journal.pone.0067479.g004

mice $[8,11,12,14]$. High intracellular calcium levels could induce apoptosis in these hair cells. In support of this hypothesis, PMCA2 delays apoptosis in hair cells with calcium overload secondary to a constitutively open TRPML3 channel [24].

The $C d h 23^{753 A}$ allele accelerates hearing loss in Atp2b2 $2^{d f w-2 J /+}$ mice [25,26]. C57BL/6J and BALB/cByJ mice carry the susceptible $C d h 23^{753 A}$ allele [26]. BALB/cJ mice are likely to also carry the $C d h 23^{753 A}$ allele as they are closely related to BALB/cByJ [27]. Hearing loss may not be penetrant in Atp2b2 $2^{\text {Deaf11/+ }}$ and Atp $2 b 2^{\text {Deaf13/+ }}$ mice on genetic backgrounds carrying the $C d h 23^{753 G}$ resistant allele, such as CBA/CaJ and C3HeB/FeJ [26]. In a human family, an Atp2b2 mutation worsens hearing loss in patients homozygous for a Cdh23 mutation [28]. In another family, a patient with hearing loss is a compound heterozygote for $C d h 23$ and Atp2b2 mutations, while three other family members with normal hearing are single heterozygotes [18]. There is no evidence linking Atp2b2 with monogenic hearing loss in humans. It is located on chromosome $3 p 25,3$ [29], a region to which no syndromic or non-syndromic hearing loss loci have been mapped [30].

\section{Supporting Information}

Table S1. Primers used in SNP genotyping.

\section{References}

(DOCX)

Table S2. Massively parallel sequencing results. (DOCX)

Table S3. One way ANOVA results for ABR thresholds. (DOCX)

\section{Acknowledgements}

The authors thank Anne Cooray for technical assistance and Mathew Salzone, Priscilla Kennedy and Melanie Howell for animal husbandry.

\section{Author Contributions}

Conceived and designed the experiments: MRC MGM BTK RAB. Performed the experiments: MRC MGM BTK RAB. Analyzed the data: MRC MGM RAB. Contributed reagents/ materials/analysis tools: BTK. Wrote the manuscript: MRC. 
1. Morton CC, Nance WE (2006) Newborn hearing screening--a silent revolution. N Engl J Med 354: 2151-2164. doi:10.1056/NEJMra050700. PubMed: 16707752

2. Shearer AE, Hildebrand MS, Sloan CM, Smith RJ (2011) Deafness in the genomics era. Hear Res 282: 1-9. doi:10.1016/j.heares. 2011.10.001. PubMed: 22016077.

3. Berne RM, Levy MN, Koeppen BM, Stanton BA (2004) The special senses. Physiology. 5th ed. St Louis: Mosby. pp. 133-148.

4. Dumont RA, Lins U, Filoteo AG, Penniston JT, Kachar B et al. (2001) Plasma membrane Ca2+-ATPase isoform $2 a$ is the PMCA of hair bundles. J Neurosci 21: 5066-5078. PubMed: 11438582.

5. Carafoli $E$ (2011) The plasma membrane calcium pump in the hearing process: physiology and pathology. Sci China Life Sci 54: 686-690. doi: 10.1007/s11427-011-4200-z. PubMed: 21786191.

6. Street VA, McKee-Johnson JW, Fonseca RC, Tempel BL, NobenTrauth K (1998) Mutations in a plasma membrane Ca2+-ATPase gene cause deafness in deafwaddler mice. Nat Genet 19: 390-394. doi: 10.1038/1284. PubMed: 9697703.

7. McCullough BJ, Tempel BL (2004) Haplo-insufficiency revealed in deafwaddler mice when tested for hearing loss and ataxia. Hear Res 195: 90-102. doi:10.1016/j.heares.2004.05.003. PubMed: 15350283.

8. Xu L, Wang Z, Xiong X, Gu X, Gao X et al. (2011) Identification of a novel point mutation of mouse Atp2b2 induced by $\mathrm{N}$-ethyl-Nnitrosourea mutagenesis. Exp Anim 60: 71-78. doi:10.1538/expanim. 60.71. PubMed: 21325754

9. Sun XY, Chen ZY, Hayashi Y, Kanou Y, Takagishi $Y$ et al. (2008) Insertion of an intracisternal A particle retrotransposon element in plasma membrane calcium ATPase 2 gene attenuates its expression and produces an ataxic phenotype in joggle mutant mice. Gene 411: 94-102. doi:10.1016/j.gene.2008.01.013. PubMed: 18280673.

10. Tsai YS, Pendse A, Moy SS, Mohri I, Perez A et al. (2006) A de novo deafwaddler mutation of Pmca2 arising in ES cells and hitchhiking with a targeted modification of the Pparg gene. Mamm Genome 17: 716-722. doi:10.1007/s00335-005-0191-z. PubMed: 16845470.

11. Spiden SL, Bortolozzi M, Di Leva F, de Angelis $\mathrm{MH}$, Fuchs $\mathrm{H}$ et al. (2008) The novel mouse mutation Oblivion inactivates the PMCA2 pump and causes progressive hearing loss. PLOS Genet 4: e1000238. PubMed: 18974863

12. Kozel PJ, Friedman RA, Erway LC, Yamoah EN, Liu LH et al. (1998) Balance and hearing deficits in mice with a null mutation in the gene encoding plasma membrane Ca2+-ATPase isoform 2. J Biol Chem 273: 18693-18696. doi:10.1074/jbc.273.30.18693. PubMed: 9668038.

13. Bortolozzi M, Brini M, Parkinson N, Crispino G, Scimemi P et al. (2010) The novel PMCA2 pump mutation Tommy impairs cytosolic calcium clearance in hair cells and links to deafness in mice. J Biol Chem 285: 37693-37703. doi:10.1074/jbc.M110.170092. PubMed: 20826782.

14. Takahashi K, Kitamura K (1999) A point mutation in a plasma membrane $\mathrm{Ca}(2+)$-ATPase gene causes deafness in Wriggle Mouse Sagami. Biochem Biophys Res Commun 261: 773-778. doi:10.1006/ bbrc.1999.1102. PubMed: 10441500

15. Bode VC (1984) Ethylnitrosourea mutagenesis and the isolation of mutant alleles for specific genes located in the $T$ region of mouse chromosome 17. Genetics 108: 457-470. PubMed: 6500258.
16. Andrews TD, Whittle B, Field MA, Balakishnan B, Zhang $Y$ et al. (2012) Massively parallel sequencing of the mouse exome to accurately identify rare, induced mutations: an immediate source for thousands of new mouse models. Open Biol 2: 120061. doi:10.1098/rsob.120061. PubMed: 22724066.

17. Laird PW, Zijderveld A, Linders $K$, Rudnicki MA, Jaenisch $R$ et al. (1991) Simplified mammalian DNA isolation procedure. Nucleic Acids Res 19: 4293. doi:10.1093/nar/19.15.4293. PubMed: 1870982.

18. Di Leva F, Domi T, Fedrizzi L, Lim D, Carafoli E (2008) The plasma membrane $\mathrm{Ca} 2+\mathrm{ATPase}$ of animal cells: structure, function and regulation. Arch Biochem Biophys 476: 65-74. doi:10.1016/j.abb. 2008.02.026. PubMed: 18328800.

19. Carpinelli MR, Burt RA, Kile BT (2012) Genetic Modifier Screens in Mice. Curr Protoc Mouse Biol 2: 75-87.

20. Zheng QY, Johnson KR, Erway LC (1999) Assessment of hearing in 80 inbred strains of mice by ABR threshold analyses. Hear Res 130: 94-107. doi:10.1016/S0378-5955(99)00003-9. PubMed: 10320101.

21. Wood JD, Muchinsky SJ, Filoteo AG, Penniston JT, Tempel BL (2004) Low endolymph calcium concentrations in deafwaddler2 $\mathrm{J}$ mice suggest that PMCA2 contributes to endolymph calcium maintenance. J Assoc Res Otolaryngol 5: 99-110. PubMed: 15357414.

22. Kazmierczak $P$, Sakaguchi $H$, Tokita J, Wilson-Kubalek EM, Milligan RA et al. (2007) Cadherin 23 and protocadherin 15 interact to form tiplink filaments in sensory hair cells. Nature 449: 87-91. doi:10.1038/ nature06091. PubMed: 17805295.

23. Assad JA, Shepherd GM, Corey DP (1991) Tip-link integrity and mechanical transduction in vertebrate hair cells. Neuron 7: 985-994. doi:10.1016/0896-6273(91)90343-X. PubMed: 1764247.

24. Grimm C, Jörs S, Heller S (2009) Life and death of sensory hair cells expressing constitutively active TRPML3. J Biol Chem 284: 13823-13831. doi:10.1074/jbc.M809045200. PubMed: 19299509.

25. Noben-Trauth K, Zheng QY, Johnson KR, Nishina PM (1997) mdfw: a deafness susceptibility locus that interacts with deaf waddler (dfw). Genomics 44: 266-272. doi:10.1006/geno.1997.4869. PubMed: 9325047.

26. Noben-Trauth K, Zheng QY, Johnson KR (2003) Association of cadherin 23 with polygenic inheritance and genetic modification of sensorineural hearing loss. Nat Genet 35: 21-23. doi:10.1038/ng1191. PubMed: 12910270

27. Les EP (1990) A Brief History of the Two Substrains of BALB/c, $\mathrm{BALB} / \mathrm{cJ}$, and BALB/cByJ Available from Animal Resources. JAX Notes Issue 443 Fall 1990

28. Schultz JM, Yang Y, Caride AJ, Filoteo AG, Penheiter AR et al. (2005) Modification of human hearing loss by plasma-membrane calcium pump PMCA2. N Engl J Med 352: 1557-1564. doi:10.1056/ NEJMoa043899. PubMed: 15829536

29. UCSC Genome Browser. http://www.genome.ucsc.edu . Accessed 23 2013

30. Camp GV, Smith R (2013) Hereditary hearing loss homepage. http:// www.hereditaryhearingloss.org. Accessed: 23 January, 2013. 